\title{
Editorial: Structure, Isotypes, Targets, and Post-translational Modifications of Immunoglobulins and Their Role in Infection, Inflammation and Autoimmunity
}

\author{
Jean Harb ${ }^{1,2,3}$, Bridget S. Wilson ${ }^{4,5}$ and Sylvie Hermouet ${ }^{2,6 *}$ \\ ${ }^{1}$ Centre de Recherche en Transplantation et Immunologie UMR1064, Inserm, Université de Nantes, Nantes, France, \\ ${ }^{2}$ CRCINA, Inserm, Université de Nantes, Université d'Angers, Nantes, France, ${ }^{3}$ Laboratoire de Biochimie, CHU de Nantes, \\ Nantes, France, ${ }^{4}$ University of New Mexico Comprehensive Cancer Center, Albuquerque, NM, United States, ${ }^{5}$ Department \\ of Pathology, University of New Mexico School of Medicine, Albuquerque, NM, United States, ${ }^{6}$ Laboratoire d'Hématologie, \\ $\mathrm{CHU}$ de Nantes, Nantes, France
}

Keywords: immunoglobulins, glycosylation, targets, inflammation, infection, autoimmunity

\section{Editorial on the Research Topic}

OPEN ACCESS

Edited by:

Deborah K. Dunn-Walters, University of Surrey, United Kingdom

Reviewed by:

Roberta Pelanda,

University of Colorado School of Medicine, United States

*Correspondence:

Sylvie Hermouet sylvie.hermouet@univ-nantes.fr

Specialty section:

This article was submitted to B Cell Biology,

a section of the journal

Frontiers in Immunology

Received: 29 May 2020

Accepted: 30 June 2020

Published: 07 August 2020

Citation:

Harb J, Wilson BS and Hermouet S (2020) Editorial: Structure, Isotypes,

Targets, and Post-translational

Modifications of Immunoglobulins and

Their Role in Infection, Inflammation

and Autoimmunity.

Front. Immunol. 11:1761.

doi: 10.3389/fimmu.2020.01761
Structure, Isotypes, Targets, and Post-translational Modifications of Immunoglobulins and Their Role in Infection, Inflammation and Autoimmunity

Infection, autoimmunity, and cancer are accompanied by inflammation, which may alter the structure and function of immunoglobulins (Ig) and consequently, their pathogenicity (1-3). In addition, the isotype also influences the pathogenicity of Igs (4). During Dengue virus infection, the removal of core fucose residues selectively enhances the affinity of IgG for Fragment crystallizable (Fc) $\gamma$ IIIa receptors, leading to increased antibody-dependent cell mediated cytotoxicity (ADCC) and decreased complement dependent cytotoxicity (CDC) (5). In patients infected by the human immunodeficiency virus (HIV), anti-gp120 antibodies are less galactosylated and sialylated in asymptomatic, long-term non-progressors, compared to symptomatic patients (6). The Fc domain of IgGs can trigger pro- or anti-inflammatory responses and there is abundant evidence that carbohydrates attached to the IgG Fc domain are essential for IgG function (7-9). The pro- or anti-inflammatory function of IgGs is mediated by different affinities for activating Fc $\gamma$ Rs (Fc $\gamma$ RI, RIIa, RIIIa, and RIIIb) and inhibiting Fc $\gamma$ RIIb expressed by immune cells (10-12). A high level of sialylation of the IgG Fc fragment decreases ADCC potential through low affinity for activating receptors and conversely, bisecting $\mathrm{N}$-acetylglucosamines on the Fc fragment are pro-inflammatory and enhance ADCC (13-16). In autoimmune diseases, such as rheumatoid arthritis, patients show low levels of IgG Fc sialylation, while increased IgG sialylation is associated with remission $(17,18)$. Thus, the glycosylation level of IgGs may explains their "protective" action. Similarly, Ig glycosylation plays an important role in IgA nephropathy, where IgA1s are deficient in galactose and not correctly cleared by anti-IgA1 antibodies (19).

The targets of Igs are also of increasing interest in human pathology, and important antigenic drivers are being discovered in monoclonal gammopathies of undetermined significance (MGUS) and myeloma, a blood cancer (20-26). The immunogenic glucolipid glucosylsphingosine (GlcSph) - also called lysoglucosylceramide (LGL1) — and infectious pathogens including EpsteinBarr virus (EBV) and hepatitis $\mathrm{C}$ virus $(\mathrm{HCV})$, were recently shown to be the targets of monoclonal IgGs in MGUS and myeloma (20-26). Monoclonal IgGs bear very low levels of sialylated 
glycans, which suggests a pro-inflammatory state and reinforces the notion that chronic antigenic stimulation and an abnormal immune response contribute to the pathogenesis of MGUS and myeloma (27). Importantly, therapies aiming at reducing the target of the monoclonal Ig can be proposed to patients. Recent reports described the beneficial effect for patients who presented a GlcSph (LGL-1)-reactive monoclonal Ig and who received treatments that reduced the level of immunogenic glucolipid; a clear reduction in monoclonal Ig was obtained for two patients (28). Similarly, antiviral treatment benefited both MGUS patients and myeloma patients with a monoclonal Ig that targeted $\operatorname{HCV}(29,30)$.

This collection constituted of 13 original articles, 1 case report and 2 reviews from 112 authors, is divided into three sections. The first section presents recent knowledge on the variability in structure and isotype of Igs in clinical contexts. The second section is devoted to the targets and post-translational modifications of Igs in specific pathological contexts. The final section describes the consequences of Ig variability and targets in terms of pathogenicity and interest for the diagnosis, prognosis, monitoring, and treatment of patients.

\section{STRUCTURE AND ISOTYPES OF IMMUNOGLOBULINS}

The structure of Igs influences their function and also their fate (half-life, for instance) and subsequently, their efficacy. In this regard, the studies of Deveuve et al. highlight the importance of the hinge region of Igs, particularly for the development of new therapeutic monoclonal antibodies (TmAbs) (Deveuve et al.). They analyzed the proteolytic cleavage of the hinge region of $\mathrm{IgG}$, which may occur by proteases of the microenvironment, including matrix metalloproteinase 12 (MMP12) or bacterial (Streptococcus piogenes) Ig-degrading enzymes (IdeS) and represents an escape mechanism to treatment by TmAbs. The authors compared the cleavage of $8 \mathrm{TmAbs}$ of different isotypes and found the IgG2 TmAb more protease resistant than IgG1 and IgG4 TmAbs, and variable IdeS-sensitivity among IgG4 and IgG1 TmAbs. They propose that the variability in the cleavage sensitivity/resistance balance among IgG1 and IgG4 TmAbs results in part from characteristics of the Fab region (Deveuve et al.). They also show that a single cleavage of IgG1 TmAbs greatly decreases their affinity for Fc $\gamma$ RIIIa and ability to induce Fc $\gamma$ RIIIa-dependent functional responses from NK cells.

Allergy is dependent on the IgE isotype. Koning et al. studied IgE VDJ sequences from allergic patients, and compared them to the $\operatorname{IgE}$ repertoire from healthy, non-atopic individuals. They report that IgE repertoires were highly oligoclonal with preferential usage of certain IGHV genes. IgE sequences had no clonal relationship with the other isotypes, carried more somatic mutations than IgM but fewer than IgG and IgA. Thus, in healthy individuals, the mutational burden of IgE suggests an origin through direct class-switching from the IgM repertoire, and presumably low affinity for antigens.

The risk of transplant rejection is also affected by the isotype of antibodies developed by patients against human leukocyte antigens (HLA). Navas et al. describe the results of the analysis of 1,285 anti-HLA antibodies identified in serum samples from 20 highly HLA-sensitized patients, and report that $36.8 \%$ of anti-HLA antibodies were C1q-binding. They found a strong association between C1q-binding ability and IgG1 strength, whereas weak or non-C1q-binding IgG2 and IgG4 subclasses were common. They conclude that the IgG1 subclass best correlates with the C1q-binding ability of anti-HLA antibodies.

\section{TARGETS AND POST-TRANSLATIONAL MODIFICATIONS OF IMMUNO-GLOBULINS IN SPECIFIC PATHOLOGICAL CONTEXTS}

\section{Targets of Immunoglobulins}

The antigenic targets of pathological Igs are relatively wellknown in the context of allergy and auto-immune diseases. In the context of B-cell malignancies, the main objective is to eliminate the malignant clone and most studies aim to characterize tumoral cells and uncover the mechanisms of their resistance to treatments. Consequently, the antigenic targets of the Igs produced by malignant B-cell clones are rarely studied. Yet there is mounting evidence that chronic antigen stimulation as an important pathogenic mechanism in the development of B-cell malignancies. For instance, patients with somaticallymutated (antigen-driven) chronic lymphocytic leukemia (CLL) have a more favorable clinical course than other CLL patients $(31,32)$. Evidence in favor of chronic antigen stimulation has also been reported in MGUS and in myeloma (20-26). CLLassociated antigens appear to be mostly autoantigens, notably cytoskeleton components, or autoantigens found in apoptotic cells and bacteria (33-35). Cases of virus (HCV), HIV-driven CLL, MGUS or myeloma appear to be relatively rare (36). In MGUS and myeloma, the targets of monoclonal IgG reported include viruses $(>25 \%$ cases, predominantly EBV and more rarely, herpes virus simplex (HSV) and HCV) and glucolipids, particularly GlcSph (LGL1) ( $15 \%$ cases) or associated enzymes (22-26). Using a new assay based on the protein micro-array technology, Bosseboeuf et al. report that the purified monoclonal Ig from $42 \%$ of IgA MGUS and myeloma patients recognize EBV EBNA-1, HCV or LGL1. Altogether, a pathogenic model of antigen-driven disease may be valid for about half of CLL, MGUS, and myeloma cases. This model offers new therapeutic approaches: in addition to current therapeutic protocols aimed at eliminating the malignant clone, one can envision therapies designed to reduce or suppress the antigen responsible for disease initiation, i.e., the target of the patient's monoclonal Ig, whenever the target can be identified (28-30).

Unfortunately, the identification of the targets of pathogenic human IgG and IgA for diagnosis and therapeutic purposes is still not possible outside research laboratories. Similarly, the targets of IgMs from healthy individuals are rarely investigated and remain poorly known. To facilitate the study of human IgM antibodies, which are characterized by polyspecificity and autoreactivity, Pashov et al. propose a new peptide array consisting of 594 
mimotopes that reflect the common IgM repertoire of 10,000 healthy donors.

\section{Post-translational Modifications and Function of Immunoglobulins}

To interpret the results of IgG functional studies, the conditions of preparation and purification of Igs are of great importance. Lopez et al. report that low $\mathrm{pH}$ exposure during IgG purification may result in aggregates that abnormally and avidly bind $\mathrm{F} c \gamma$ receptors. These authors compared Protein $G$ purification of IgG (at low $\mathrm{pH}$ ) with an immunoaffinity method which elutes IgG at physiological $\mathrm{pH}$, and investigated several factors known to impact Fc functionality and influence $\mathrm{Fc} \gamma \mathrm{R}$ binding, including IgG subclass, $N$-glycosylation, aggregation, and conformational changes. They show that low $\mathrm{pH}$ elution of IgG enhances their recognition of Fc $\gamma$ Rs, and increases IgG aggregation. Thus, differences in IgG purification methods may explain the poor reproducibility of studies of $\mathrm{Fc}$-mediated antibody functions.

The important role played in immunity by the $\mathrm{N}$-linked glycosylation of the Fc region of Igs is well-established but the function of $\mathrm{N}$-linked glycosylation of the variable domains of Igs is less well-known. In their review, Vletter et al. report that $\mathrm{N}$-linked glycans are present on autoantibodies, notably in rheumatoid arthritis, and in patients with B-cell follicular lymphoma (FL). N-linked glycosylation of the variable domain of Igs may confer a selective advantage, through interaction with lectins and/or microbiota. They analyzed the characteristics of autoantibodies and those of Igs from FL patients and healthy donors and found differences in variable domain glycan distribution, frequency and glycan composition, which led them to propose a classification of diseases according to the specific Ig variable domain glycosylation patterns observed in patients.

Sialylation may also modify therapeutic IgGs. Shaffert et al. analyzed changes in human intravenous IgG (IVIg) sialylation upon injection in mice deficient in B cells or lacking the sialyltransferase 1 , which catalyzes the addition of $\alpha 2,6$ linked sialic acid residues and conclude that the glycosylation of therapeutic IgGs is stable in vivo Schaffert et al.. Only a very small fraction of IgGs acquired sialic acid structures, mostly in the Fab portion, not in the Fc portion.

\section{CONSEQUENCES IN TERMS OF DIAGNOSIS, PROGNOSIS, MONITORING OF PATIENTS, AND THERAPY}

The detection of monoclonal or/and polyclonal Igs with identified targets is becoming of increasing importance in different clinical contexts, including severe infection, chronic inflammation, and certain blood cancers. It is also necessary to better understand the effects of therapeutic monoclonal antibodies used in the clinic, alone or associated with other treatments.

\section{Infection}

The interest of understanding the Ig response of patients in context of acute infection is illustrated by the report by
Bloomfield et al., who describe the case of an infant who presented with a normal C-reactive protein (CRP) level despite severe septic shock following Staphylococcus aureus infection, with clear biological evidence of systemic inflammation. Bloomfield et al. suspected a defect in the interleukin-6 (IL6)/CRP axis, which was confirmed by the presence of neutralizing anti-IL- 6 autoantibodies in the child's serum. These findings are of importance since clinical interference of IL-6 signaling, for instance with IL-6 receptor-targeting therapeutic antibodies such as tocilizumab or sarilumab, may alter IL-6-mediated innate immune responses and compromise host resistance to infections.

The complex role played by Igs in chronic infection is illustrated in the review by McLean et al. on the mechanisms of tuberculosis reactivation in individuals with comorbidities. They describe the Ig responses to Mycobacterium tuberculosis of patients with chronic conditions, such as co-infection with HIV, diabetes or kidney diseases, where inflammation may facilitate tuberculosis re-activation. McLean et al. propose that inflammatory IgG profiles may be important biomarkers for the detection of progressive tuberculosis. More studies are needed to distinguish inflammatory antibody profiles that are the consequences of co-morbidities from those that contribute to the reactivation of tuberculosis.

Regarding severe viral infections, neutralizing antibodies hold great promise both for antibody-based therapeutic intervention and for vaccine design. This is illustrated by the paper by Gao et al., who applied next-generation sequencing (NGS) to probe the development of ZK2B, a potent E DIII-specific antibody protective against Zika virus (ZIKV), isolated from a convalescent individual. The NGS-derived, germline-like ZK2B10 somatic variants neutralized ZIKV and protected mice from ZIKV challenge, without cross-reactivity with Dengue virus. Site-directed mutagenesis identified residues essential to the functional maturation of ZK2B10. The repertoire and lineage features unveiled in this study should help elucidate the developmental process and protective potential of antiZIKV antibodies.

\section{Auto-Immunity}

Gray et al. report on a rapidly progressive glomerulonephritis reproducing the auto-immune Goodpasture's disease (GP), caused by anti-glomerular basement membrane (GBM) antibodies developed after allogenic haematopoietic stem cell transplantation (HSCT). In GP, autoantibodies bind neoepitopes formed upon disruption of the structure of $\alpha 345 \mathrm{NC} 1$ hexamer, a critical domain of $\alpha 345$ collagen IV scaffolds. Upon hexamer disruption, $\alpha 3$ and $\alpha 5 \mathrm{NC1}$ subunits become immunogens. Gray et al.'s is the first report of allo-incompatability and antigenic specificity in anti-GBM disease after allogenic HSCT. Both the patient and donor presented with the Goodpasture's susceptibility HLA-allele $D R B 1^{*} 1501$, and the patient's anti-GBM antibodies recognized the $\mathrm{E}_{\mathrm{A}}$ epitope of the $\alpha 3 \mathrm{NC} 1$ monomer of collagen IV. Auto-antibody binding to native $\alpha 345 \mathrm{NC} 1$ hexamer was minimal, and there were no polymorphic differences between the donor's and recipient's collagen IV genes. The authors conclude that their patient's was a case of classical GP disease, the anti-GBM antibodies emerging post transplantation 
from the donor immune system. This hypothesis is supported by the finding that native a345 NC1 hexamer was not pathogenic in an animal model of GP disease, whereas immunization with dissociated hexamers induced glomerulonephritis (Gray et al.).

Another example is provided by systemic lupus erythematosus (SLE), where Zhang et al. investigated the role of IgG in spleen inflammation. They report that lupus IgGs are important pathological factors involved in the initiation of inflammation and further germinal center (GC) and plasma cell formation. Macrophages of the splenic marginal zone were dispensable for the GC response induced by lupus IgG, while red pulp macrophages were important for GC responses. Furthermore, lupus IgGs promoted inflammation and GC formation through the macrophage-mediated secretion of TNF- $\alpha$. Interestingly, Syk

\section{REFERENCES}

1. Scallon BJ, Tam SH, McCarthy SG, Cai AN, Raju TS. Higher levels of sialylated Fc glycans in immunoglobulin $G$ molecules can adversely impact functionality. Mol. Immunol. (2007) 44:1524-34. doi: 10.1016/j.molimm.2006.09.005

2. Dalziel M, Crispin M, Scanlan CN, Zitzmann N, Dwek RA. Emerging principles for the therapeutic exploitation of glycosylation. Science. (2014) 343:1235681. doi: 10.1126/science. 1235681

3. Parekh RB, Dwek RA, Sutton BJ, Fernandes DL, Leung A, Stanworth D, et al. Association of rheumatoid arthritis and primary osteoarthritis with changes in the glycosylation pattern of total serum IgG. Nature. (1985) 316:452-7. doi: 10.1038/316452a0

4. Nimmerjahn F, Ravetch JV. Divergent immunoglobulin $\gamma$ subclass activity through selective $F_{c}$ receptor binding. Science. (2005) 310:1510-2. doi: 10.1126/science. 1118948

5. Wang TT, Sewatanon J, Memoli MJ, Wrammert J, Bournazos S, Bhaumik SK, et al. IgG antibodies to dengue enhanced for Fc $\gamma$ RIIIA binding determine disease severity. Science. (2017) 355:395-8. doi: 10.1126/science.aai8128

6. Ackerman ME, Crispin M, Yu X, Baruah K, Boesch AW, Harvey DJ, et al. Natural variation in Fc glycosylation of HIV-specific antibodies impacts antiviral activity. J. Clin. Invest. (2013) 123:2183-92. doi: 10.1172/JCI65708

7. Kaneko Y, Nimmerjahn F, Ravetch JV. Anti-inflammatory activity of immunoglobulin G resulting from Fc sialylation. Science. (2006) 313:6703. doi: $10.1126 /$ science. 1129594

8. Nimmerjahn F. Activating and inhibitory FcgammaRs in autoimmune disorders. Springer Semin. Immunopathol. (2006) 28:305-19. doi: 10.1007/s00281-006-0052-1

9. Anthony RM, Nimmerjahn F, Ashline DJ, Reinhold VN, Paulson JC, Ravetch JV. Recapitulation of IVIG anti-inflammatory activity with a recombinant IgG Fc. Science. (2008) 320:373-6. doi: 10.1126/science.1154315

10. Anthony RM, Wermeling F, Karlsson MCI, Ravetch JV. Identification of a receptor required for the anti-inflammatory activity of IVIG. Proc Natl Acad Sci USA. (2008) 105:19571-8. doi: 10.1073/pnas.0810163105

11. Schwab I, Mihai S, Seeling M, Kasperkiewicz M, Ludwig RJ, Nimmerjahn F. Broad requirement for terminal sialic acid residues and Fc $\gamma$ RIIB for the preventive and therapeutic activity of intravenous immunoglobulins in vivo. Eur J Immunol. (2014) 44:1444-53. doi: 10.1002/eji.201344230

12. Washburn N, Schwab I, Ortiz D, Bhatnagar N, Lansing JC, Medeiros A, et al. Controlled tetra-Fc sialylation of IVIg results in a drug candidate with consistent enhanced anti-inflammatory activity. Proc Natl Acad Sci USA. (2015) 112:E1297-306. doi: 10.1073/pnas.1512309112

13. Umaña P, Jean-Mairet J, Moudry R, Amstutz H, Bailey JE. Engineered glycoforms of an antineuroblastoma IgG1 with optimized antibodydependent cellular cytotoxic activity. Nat. Biotechnol. (1999) 17:17680. doi: $10.1038 / 6179$ inhibitor treatment suppressed the changes in the histopathology of the spleen induced by lupus IgGs.

\section{CONCLUSION}

Accumulating new knowledge of the structure, targets, and glycosylation of pathogenic Igs should rapidly translate into improved diagnosis and treatments for patients suffering from acute or chronic infection, chronic inflammation, autoimmunity, or B-cell malignancies.

\section{AUTHOR CONTRIBUTIONS}

All authors listed have made a substantial, direct and intellectual contribution to the work, and approved it for publication.

14. Gasdaska JR, Sherwood S, Regan JT, Dickey LF. An afucosylated anti-CD20 monoclonal antibody with greater antibody-dependent cellular cytotoxicity and B-cell depletion and lower complementdependent cytotoxicity than rituximab. Mol Immunol. (2012) 50:134-41. doi: 10.1016/j.molimm.2012.01.001

15. Quast I, Keller CW, Maurer MA, Giddens JP, Tackenberg B, Wang L-X, et al. Sialylation of IgG Fc domain impairs complement-dependent cytotoxicity. J Clin Invest. (2015) 125:4160-70. doi: 10.1172/JCI82695

16. Schwab I, Biburger M, Krönke G, Schett G, Nimmerjahn F. IVIg-mediated amelioration of ITP in mice is dependent on sialic acid and SIGNR1. Eur J Immunol. (2012) 42:826-30. doi: 10.1002/eji.201142260

17. Parekh RB, Roitt IM, Isenberg DA, Dwek RA, Ansell BM, Rademacher TW Galactosylation of IgG associated oligosaccharides: reduction in patients with adult and juvenile onset rheumatoid arthritis and relation to disease activity. Lancet. (1988) 1:966-9. doi: 10.1016/S0140-6736(88)91781-3

18. van de Geijn FE, Wuhrer M, Selman MH, Willemsen SP, de Man YA, Deelder AM, et al. Immunoglobulin G galactosylation and sialylation are associated with pregnancy-induced improvement of rheumatoid arthritis and the postpartum flare: results from a large prospective cohort study. Arthritis Res Ther. (2009) 11:R193. doi: 10.1186/ar2892

19. Novak J, Barratt J, Julian BA, Renfrow MB. Aberrant glycosylation of the IgA1 molecule in IgA nephropathy. Semin Nephrol. (2018) 38:46176. doi: 10.1016/j.semnephrol.2018.05.016

20. Hermouet S, Corre I, Gassin M, Bigot-Corbel E, Sutton CA, Casey JW. Hepatitis C virus, human herpesvirus-8 and the development of plasma cell leukemia. New Engl J Med. (2003) 348:178-9. doi: 10.1056/NEJM200301093480219

21. Bigot-Corbel E, Gassin M, Corre I, Le Carrer D, Delaroche O, Hermouet $\mathrm{S}$. Hepatitis $\mathrm{C}$ virus (HCV) infection, monoclonal immunoglobulin specific for HCV core protein, plasma-cell malignancy. Blood. (2008) 112:43578. doi: 10.1182/blood-2008-07-167569

22. Nair S, Branagan AR, Liu J, Boddupalli CS, Mistry PK, Dhodapkar M V. Clonal immunoglobulin against lysolipids in the origin of myeloma. New Engl J Med. (2016) 374:555-61. doi: 10.1056/NEJMoa1508808

23. Bosseboeuf A, Feron D, Tallet A, Rossi C, Charlier C, Garderet L, et al. Monoclonal IgG in MGUS and multiple myeloma target infectious pathogens. J Clin Invest Insight Oct. (2017) 5: 95367. doi: 10.1172/jci.insight.95367

24. Nair S, Sng J, Sekhar Boddupalli C, Seckinger A, Chesi M, Fulciniti M, et al. Antigen-mediated regulation in monoclonal gammopathies and myeloma. $J$ Clin Invest Insight. (2018) 3:e98259. doi: 10.1172/jci.insight.98259

25. Preuss KD, Hollak CEM, Fadle N, van Oers M, Regitz E, Pfreundschuh M. Saposin C is a frequent target of paraproteins in Gaucher diseaseassociated MGUS/multiple myeloma. Br J Haematol. (2019) 184:38491. doi: 10.1111/bjh.15659

26. Bosseboeuf A, Mennesson N, Allain-Maillet S, Tallet A, Piver E, Moreau C, et al. Characteristics of MGUS and multiple myeloma according to the target 
of monoclonal immunoglobulins, glucosylsphingosine, or epstein-barr virus EBNA-1. Cancers. (2020) 12:E1254. doi: 10.3390/cancers12051254

27. Bosseboeuf A, Allain S, Mennesson N, Tallet A, Rossi C, Garderet L, et al. Proinflammatory state in MGUS and Myeloma is characterized by low sialylation of pathogen-specific and other monoclonal and polyclonal immunoglobulin G. Front. Immunol. (2017) 8:1347. doi: 10.3389/fimmu.2017.01347

28. Nair S, Bar N, Xu ML, Dhodapkar M, Mistry PK. Glucosylsphingosine but not Saposin C, is the target antigen in Gaucher disease-associated gammopathy. Mol Genet Metab. (2020) 129:286-91. doi: 10.1016/j.ymgme.2020. 01.009

29. Panfilio S, D’Urso P, Annechini G, D'Elia GM, De Angelis F, Stefanizzi C, et al. Regression of a case of Multiple Myeloma with antiviral treatment in a patient with chronic HCV infection. Leuk Res Rep. (2013) 2:3940. doi: 10.1016/j.lrr.2013.01.002

30. Rodríguez García A, Linares M, Mennesson N, Sanchez-Vega B, Sanchez R, Alonso Fernandez R, et al. The role of Hepatitis C virus in the development of multiple myeloma: a case study. 60th Annual Meeting of the American Society of Hematology (ASH), San Diego, CA, USA, December 1-4, 2018. Abstract Nbr: 5592, Submission ID: 112842. Blood. (2018) 132:5592. doi: 10.1182/blood-2018-99-112842

31. Damle RN, Wasil T, Fais, F, Ghiotto F, Valleto A, Allen SL, et al. Ig $\mathrm{V}$ gene mutation status and CD38 expression as novel prognostic indicators in chronic lymphocytic leukemia. Blood. (1999) 94:1840-7. doi: 10.1182/blood.V94.6.1840.418k06_1840_1847

32. Hamblin TJ, Davis Z, Gardiner A, Oscier DG, Stevenson FK. Unmutated Ig $\mathrm{VH}$ genes are associated with a more aggressive form of chronic lymphocytic leukemia. Blood. (1999) 94:1848-54. doi: 10.1182/blood.V94.6.1848.418k05_1848_1854
33. Chiorazzi N, Hatzi K, Albesiano E. B-cell chronic lymphocytic leukemia, a clonal disease of B lymphocytes with receptors that vary in specificity for (auto)antigens. Ann N Y Acad Sci. (2005) 1062:1-2. doi: 10.1196/annals.1358.002

34. Catera R, Silverman GJ, Hatzi K, Seiler T, Didier S, Zhang L, et al. Chronic lymphocytic leukemia cells recognize conserved epitopes associated with apoptosis and oxidation. Mol Med. (2008) 14:665-74. doi: 10.2119/2008-00102.Catera

35. Lanemo Myhrinder A, Hellqvist E, Sidorova E, Söderberg A, Baxendale $\mathrm{H}$, Dahle C, et al. A new perspective: molecular motifs on oxidized LDL, apoptotic cells, and bacteria are targets for chronic lymphocytic leukemia antibodies. Blood. (2008) 111:3838-48. doi: 10.1182/blood-2007-11-125450

36. Hwang K-K, Trama AM, Kozink DM, et al. IGHV1-69 B cell chronic lymphocytic leukemia antibodies cross-react with HIV-1 and hepatitis c virus antigens as well as intestinal commensal bacteria. PLoS ONE. (2014) 9:e90725. doi: 10.1371/journal.pone.0090725

Conflict of Interest: The authors declare that the research was conducted in the absence of any commercial or financial relationships that could be construed as a potential conflict of interest.

Copyright (c) 2020 Harb, Wilson and Hermouet. This is an open-access article distributed under the terms of the Creative Commons Attribution License (CC BY). The use, distribution or reproduction in other forums is permitted, provided the original author(s) and the copyright owner(s) are credited and that the original publication in this journal is cited, in accordance with accepted academic practice. No use, distribution or reproduction is permitted which does not comply with these terms. 